\title{
Antifungal Effect on Candida Albicans of Laurel, Coconut and Coriander Seed Oil
}

\section{Cansel C*, Huseyin HD, Seyma AB, Ali G, Sidika BO, Yasemin G, Beril K, Hale Feyza B and Mevlut B}

Selcuk University, Turkey

*Corresponding author: Cansel Candan, Selcuk University, Zade Vital

\section{Research Article}

Volume 3 Issue 3

Received Date: June 11, 2019

Published Date: July 05, 2019

DOI: $10.23880 /$ oajpr-16000179

Pharmaceutical Chemicals Food Industry and Trade Inc., Buyukkayacık OSB Mah. Guzel Konak Sok. 8B-1 Selçuklu/KONYA, Turkey, Tel: +90 53755819 53; Email: cak@zade.com.tr

\section{Abstract}

Candida albicans (C.P. Robin) mushroom has the highest pathogenicity among other candida species. The high amounts of linoleic acid (18:2), and oleic acid (C 18: 1, 9 octadecenoic acid) in the biphasic mutant fungus Candida albicans in vitro by using cold press method from Laurel and Coriander seeds, and (-)-isopulegol monoterpen component were cultured in the microbiology laboratory of the ZadeVital R\&D center. Kirby-Bauer disc diffusion method was used in the passages. The proportions of fatty acids were measured by GC (Gas Chromatography), and the free fatty acids by GC MS (Gas Chromatogram-Mass Spectrometry). The oils extracted from the bay and coriander seeds by cold pressing were absorbed into sterile antibiotic discs. Nystatin antibiotic was used as a reference. Antibiograms were checked every 2 days for 24 hours. The zones formed in the passages were measured in mm and resistance and sensitivity a nalyzes were performed against Candida albicans strain oils. We have found that (-)-isopulegol monotherpen is a determinant of antifungal properties compared to other fatty acids. In this study, we have seen that oils extracted by cold pressing from laurel and coriander seeds have topical antifungal properties on Candida albicans species.

Keywords: Laurel; Coriander; Fatty Acid; Disk Diffusion; Nystatin; Pathogen; Coconut

\section{Introduction}

Fatty acids are known to have antibacterial and antifungal activity. The chemical composition of fatty acids and the $\mathrm{pH}$ of the medium play an important role in these compounds' ability to inhibit fungi [1,2]. The cell membrane has an essential general role of maintaining cell order and integrity and a number of disease-control mechanisms involve compounds that directly (by partitioning into the membrane and inducing disorder) or indirectly (by inhibiting fatty acid biosynthetic pathways) target the phospholipids of the cell membrane [3]. This is also true for certain fatty acids or their derivatives. Recent research has also shown that 2-hexadecynoic acid, a 2alkynoic fatty acid, has antibacterial activity against Mycobacterium tuberculosis and that linoleic acid (18:2), a polyunsaturated fatty acid, has antifungal activity against several plant pathogenic fungi [4]. 


\section{Open Access Journal of Pharmaceutical Research}

Using the oil extracted by cold pressing from Laurel, Coconut and Coriander seeds, a study was conducted on the topical antifungal effect of high amounts of the active substances linoleic acid (18:2) and oleic acid (C 18: 1, 9 octadecenoic acid) and the (-) -isopulegol monoterpen on Candida albicans [5].

\section{Isopulegol}

Isopulegol (chemical formula: $\mathrm{C} 10 \mathrm{H} 180$ ) is a pmenthane monoterpenoid present in the volatile oils of many plants. Generally it is present at high amounts in the mytraceae family (especially in eucalyptus trees) [6]. A study showed that Eucalyptus citriodora contains \%16.1 isopulegol, and argued that the total volatile oil contents be used as herbal insecticide [7]. In another study conducted to determine the inhibition activity of 28 different volatile components on Candida Albicans, isopulegol showed a strong biofilm inhibition activity [8].

\section{Material and Method}

\section{Material}

The seeds from which the oils used in the study were extracted were procured from HASMERAM A.Ş. (Konya). The oils were obtained by cold pressing from the seeds, and stored in 200-ml glass jars for the necessary analyses.

\section{Method}

Determination of fatty acids by gas chromatography (GC) instrument: Analysis was performed by GC (Shimadzu, 2010 Plus AF) to determine the contents for each fatty acid. The operating conditions for the instrument were as follows (Table 1).

\begin{tabular}{|c|c|}
\hline Detector & Flame Ionization Detector (FID) \\
\hline Column & $100 \mathrm{~m} \mathrm{x} 0.25 \mathrm{~mm} \mathrm{ID}, 0.2 \mu \mathrm{m}$ Silica Column \\
\hline Detector Temperature & $260^{\circ} \mathrm{C}$ \\
\hline Makeup Gas Type / Flow & Nitrogen $/ 30.0 \mathrm{~mL} / \mathrm{min}$ \\
\hline Injection Block Temperature & $250^{\circ} \mathrm{C}$ \\
\hline Injection Volume & $1.0 \mu \mathrm{L}$ \\
\hline Injection Block Pressure & $163.5 \mathrm{kPa}$ \\
\hline Injection Block Total Flow & $114.1 \mathrm{~mL} / \mathrm{min}$ \\
\hline Carrier Gas & $\mathrm{N} 2$ \\
\hline Temperature Program & $\begin{array}{c}\text { Start with an initial oven temperature of } 140^{\circ} \mathrm{C}, \text { hold for } 5 \text { minutes at } 140^{\circ} \mathrm{C}, \\
\text { increase to } 240^{\circ} \mathrm{C} \text { at } 4{ }^{\circ} \mathrm{C} / \mathrm{min}, \text { hold for } 20 \text { minutes. }\end{array}$ \\
\hline
\end{tabular}

Table 1: GC Operating Conditions.

Procedure: Weigh $60 \mathrm{mg}$ of oil sample into a screw-cap tube. Add $2 \mathrm{~mL}$ of $2 \mathrm{~N}$ Methanolic Potassium hydroxide $(\mathrm{KOH})$ solution. Mix for 5 minutes with a vortex mixer. Add $2 \mathrm{~mL}$ of $\mathrm{n}$-heptane to the oil sample to which Methanolic Potassium hydroxide was added, and mix for 1 minute with a vortex mixer. Centrifuge the vortex-mixed oil sample at $3000 \mathrm{rpm}$ for 5 minutes. Collect the supernatant (organic phase) of the centrifuged oil sample, pass through a $0.45-\mu \mathrm{m}$ filter, transfer to a GC vial and enter into the system.

Determination of volatile components by gas chromatography -mass spectroscopy (GC-MS)

Analysis was performed by the instrument (Shimadzu, QP2010 Ultra/AOC/5000 SPME) to determine the volatile component contents for each oil. The operating conditions for the instrument were as follows (Table 2).

\begin{tabular}{|c|c|}
\hline Detector & FID $/ \mathrm{MS}$ \\
\hline Column Oven Temperature & $40.0^{\circ} \mathrm{C}$ \\
\hline Injection Temperature & $250.0^{\circ} \mathrm{C}$ \\
\hline Injection Mode & Split \\
\hline Pressure & $101.1 \mathrm{kPa}$ \\
\hline Flow Control Mode & Pressure \\
\hline Total Flow & $40.8 \mathrm{~mL} / \mathrm{min}$ \\
\hline Column Flow & $1.80 \mathrm{~mL} / \mathrm{min}$ \\
\hline Purge Flow & $3.0 \mathrm{~mL} / \mathrm{min}$ \\
\hline Split Ratio & 20 \\
\hline High Pressure Injection Pressure & $200.0 \mathrm{kPa}$ \\
\hline
\end{tabular}

Table 2: GC-MS Operating Conditions.

Procedure: Weigh 3-5 grams of oil sample that was passed through a $0.45-\mu \mathrm{m}$ filter into a screw-cap $10-\mathrm{ml}$ glass vial, and enter into the system. 


\section{Open Access Journal of Pharmaceutical Research}

Determination of Antifungal Activity by Kirby Bauer Method: Nystatin was used as the reference to determine the activity of laurel seed oil, coriander seed oil and coconut oil on the fungi type C. Albicans. Blank antibiogram discs were impregnated with nystatin (for reference), laurel seed oil, coriander seed oil and coconut oil, and prepared.

C. Albicans was plated onto 12 petri dishes, 6 onto tryptic soy agar and 6 onto Sabouraud dextrose agar. The discs impregnated with nystatin and oils were placed into the petri dishes and incubated.

Incubation conditions: $33 \pm 1^{\circ} \mathrm{C}$, under normal atmosphere conditions, for 24 hours - 48 hours.

\section{Results and Discussion}

The results of the study conducted to determine the characteristics of the oils by Gas Chromatography are given in Table 3.

\begin{tabular}{|c|c|c|c|}
\hline Fatty Acid & Laurel Seed Oil (\% Area) & Coriander Seed Oil (\% Area) & Coconut Oil (\%Area) \\
\hline Butyric Acid (C 4:0) & - & - & 0.64 \\
\hline Caproic Acid (C 6:0) & - & - & 0.57 \\
\hline Caprylic Acid (C 8:0) & - & - & 7.72 \\
\hline Capric Acid (C 10:0) & 0.17 & 0.63 & - \\
\hline Undecanoic Acid (C 11:0) & 0.06 & - & 51.29 \\
\hline Lauric Acid (C 12:0) & 13.81 & 0.03 & 20 \\
\hline Myristic Acid (C 14:0) & 0.62 & 3.11 & - \\
\hline Palmitic Acid (C 16:0) & 14.15 & 0.16 & - \\
\hline Palmitoleic Acid (C 16:1) & 0.23 & 0.03 & 2.34 \\
\hline Heptadecanoic Acid (C 17:0) & 0.02 & 0.73 & 4.04 \\
\hline Stearic Acid (C 18:0) & 1.61 & 82.06 & 0.66 \\
\hline Oleic Acid (C 18:1) & 41.12 & 12.77 & - \\
\hline Linoleic Acid (C 18:2) & 26.68 & 0.07 & - \\
\hline Arachidic Acid (C 20:0) & 0.15 & 0.05 & - \\
\hline Gondoic Acid (C 20:1) & 0.49 & 0.18 & - \\
\hline Linolenic Acid (C 18:3) & 0.69 & 0.03 & - \\
\hline Behenic Acid (C 22:0) & 0.09 & 0.02 & \\
\hline Erucic Acid (C 22:1) & - & Cor & \\
\hline
\end{tabular}

Table 3: Results of the Analysis by Gas Chromatography for Laurel Seed Oil, Coriander Seed Oil and Coconut Oil.

Levels of oleic acid and linoleic acid were determined as an important measure for determination of antifungal effect. Oleic acid and linoleic acid, present at high amounts in laurel and coriander seed oil while being present at low amounts in coconut. This contributes to the antifungal effect of laurel and coriander seed oil, but no antifungal effect has been found in coconut oil.

The result of the analysis of volatile components by GC-MS to determine the effect of volatile components of oils is shown in Table 4.

\begin{tabular}{|c|c|c|c|}
\hline Compound & Laurel Oil (Area / Height) & Coriander Oil (Area / Height) & Coconut Oil (Area / Height) \\
\hline$(-)$ - Isopulegol & 11.47 & 8.54 & - \\
\hline
\end{tabular}

Table 4: (-) - Results of Isopulegol Analysis by GC-MS for Laurel Seed Oil, Coriander Seed Oil and Coconut Oil.

The study revealed that the volatile component isopulegol is associated with the antifungal effect of laurel and coriander seed oil. The isopulegol component present at high amounts in both fixed oil types provides antifungal effect on the fungi type. No isopulegol was found in coconut oil.

The changes in the petri dishes as a result of microbiological growth are shown below (Figures 1-4). 


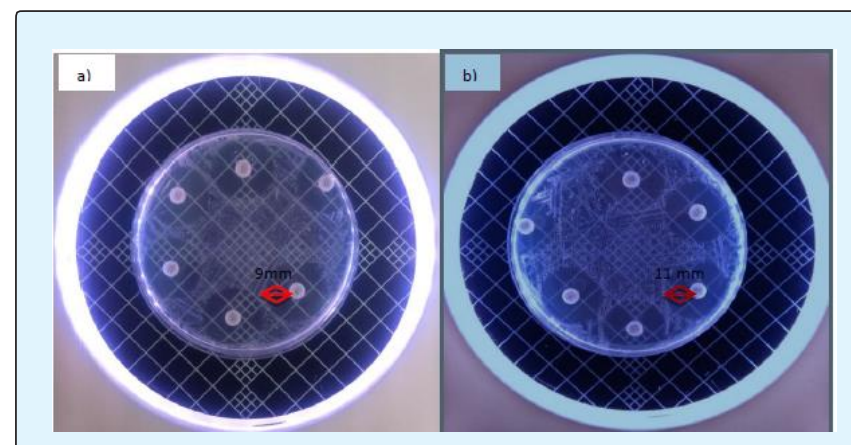

Figure 1: a) Nystatin; at the end of the 24-hour incubation period, b) Nystatin; at the end of the 48hour incubation period.

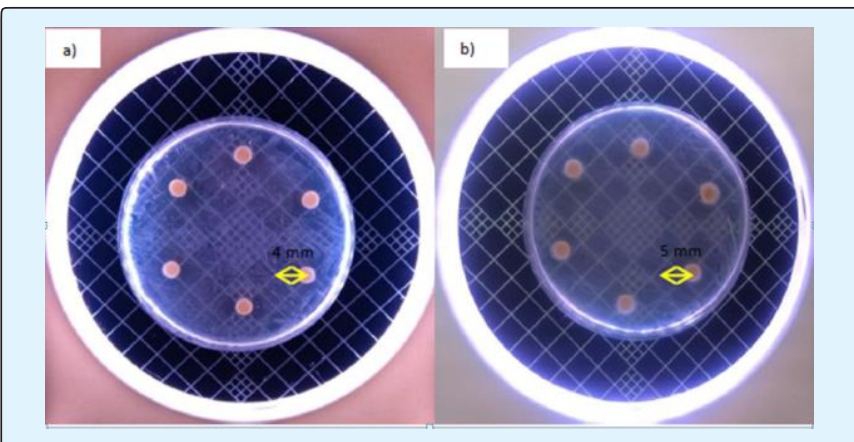

Figure 2: a) Laurel Seed Oil; at the end of the 24-hour incubation period, b) Laurel Seed Oil; at the end of the 48-hour incubation period.

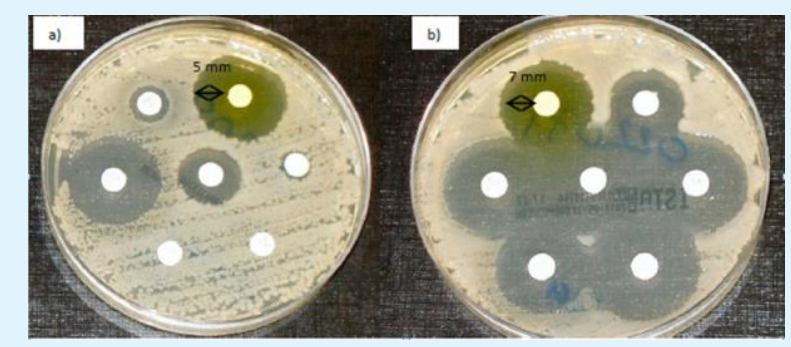

Figure 3: a) Coriander Seed Oil; at the end of the 24hour incubation period, b) Coriander Seed Oil; at the end of the 48-hour incubation period.

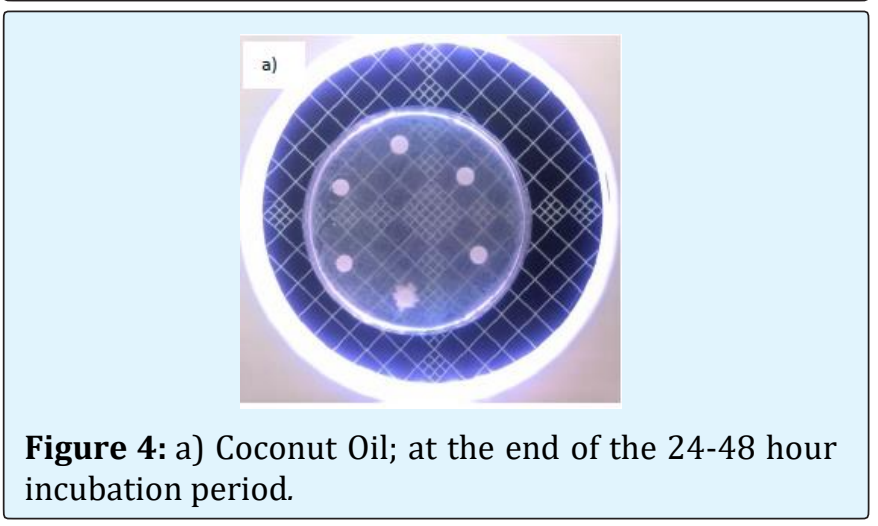

Figure 1 shows the sensitivity of the type $C$. Albicans to nystatin (used as the reference). The zone was $9 \mathrm{~mm}$ at the end of the 24-hour period and $11 \mathrm{~mm}$ at the end of the 48-hour period. Figure 2 shows the effect of laurel seed oil on the sensitivity of the type C. Albicans at the end of the 24-hour and 48-hour periods. The zone was $4 \mathrm{~mm}$ at the end of the 24-hour period and $5 \mathrm{~mm}$ at the end of the 48-hour period. Figure 3 shows the antifungal effect of coriander seed oil at the end of the 24-hour and 48-hour periods. The zone was $5 \mathrm{~mm}$ at the end of the 24-hour period and $7 \mathrm{~mm}$ at the end of the 48-hour period. Figure 4 shows that after incubation with coconut oil, the type $C$. Albicans was resistant to coconut oil and coconut oil did not form any zone for this type.

\section{Conclusion}

The results obtained revealed that laurel seed oil and coriander seed oil show antifungal effect against the fungi type C. Albicans. It was concluded that the antifungal effect is due to isopulegol, oleic acid and linoleic acid contained is these oils.

On the other hand, it was found that coconut oil is not effective since it contains low levels of oleic acid and linoleic acid and does not contain the volatile compound isopulegol.

\section{References}

1. Altieri C, Bevilacqua A, Cardillo D, Sinigaglia M (2009) Antifungal activity of fatty acids and their monoglycerides against Fusarium spp. in a laboratory medium. International Journal of Food Science and Technology 44(2): 242-245.

2. Gershon H, Shanks L (1978) Antifungal activity of fatty acids and derivatives: structure-activity relationships. In: Kabara JJ (Ed.), The Pharmacological Effect of Lipids. American Oil Chemist's Society, Champaign, pp: 51-62.

3. Avis TJ (2007) Antifungal compounds that target fungal membrane: application in plant disease control. Canadian Journal of Plant Pathology 29(4): 323-329.

4. Carballeira NM (2008) New advances in fatty acids as antimalarial, antimycobacterial and antifungal agents-a review. Progress in Lipid Research 47(1): 50-61. 


\section{Open Access Journal of Pharmaceutical Research}

5. Liu S, Weibin R, Jing L, Hua X, Jingan W, et al. (2008) Biological control of phytopathogenic fungi by fatty acids. Mycopathologia 166(2): 93-102.

6. Dudai N, Weinberg ZG, Larkov O, Ravid U, Ashbell G, et al. (2001) Changes in Essential Oil During EnzymeAssisted Ensiling of Lemongass (Cymbopogon citratus Stapf.) and Lemon Eucalyptus (Eucalyptus citridora Hook). J Agric Food Chem 49(5): 2262-2266.
7. Jang M, Kim J, Yoon KA, Lee SH, Park CG (2017) Biological Activity of Myrtaceae Plant Essential Oils and Their Major Components against Drosophila Suzukii (Diptera: Drosophilidae). Pest Management Science 73(2): 404-409.

8. Jayant S (2013) Terpenoids of Plant Origin İnhibit Morphogenesis, Adhesion, and Biofilm Formation by Candida Albicans. Biofouling 29(1): 87-96. 